\title{
Research on the Orientation and Reform of Chinese Course in Primary School
}

\author{
Liu Dongmei
}

Teacher's College of BeiHua University, China

\author{
Keywords: Orientation, Reform, Primary School Chinese Course
}

\begin{abstract}
Primary school language is an indispensable part of quality education and it is the basic curriculum to develop students' sound personality and improve the overall quality of students. However, in fact, many colleges and universities have the different construction standards, the beginning of primary school language courses is not the same, some schools do not pay attention to language teaching and cannot clearly define the positioning of language courses and teachers cannot be devoted to the language teaching.
\end{abstract}

\section{Introduction}

Throughout the development of primary school language curriculum and teaching reform, primary school language education can be "returned to charm", so that it is more on the basis of absorption and reference to multiculturalism and vitality. The new curriculum reform of primary school language provides rich resources for primary school Chinese course research and classroom teaching, which provides scientific basis for curriculum decision and teaching concept. However, we should reflect on the primary school language curriculum and teaching reform of the problem consciousness? Or, to solve the primary school language "new curriculum reform" the fundamental way out of the reform? Reflections need to reflect and criticize, but reflection and criticism, not to criticize and criticized, but not with the reform sing to Taiwan. In short, the ultimate goal of curriculum and teaching reflection is nothing more than to make primary school language education theory, education reform thinking from the fuzzy trend clear, and gradually guide teachers to understand the educational reform clear and thorough. It is for this purpose that we reflect on the perplexities of primary school language curriculum and teaching reform, and rationally explore the substantive causes of these problems with a view to the development of primary school language education reform.

\section{The Correct Positioning of Primary School Chinese Courses}

Chinese language curriculum to be almost their own humanistic characteristics, to adapt to the development of contemporary humanities, cultivate all aspects of comprehensive development of talent, in the actual work of the school, to do further refinement work, held a language course seminar, In order to cultivate the quality of the curriculum, we should adopt the correct method to cultivate students' interest in learning, integrate the language and culture, so that students can understand the comprehensive Chinese culture and master the things that appreciate things. In the process of reading literary works, to develop a good reading habit, while the students' thinking, morality, value, aesthetic education and training. Primary school language is not like secondary school language teaching in order to cope with college entrance examination, primary school language to focus on the cultivation of humanistic rationality, improve students think about the depth of life.

Primary school language professor is a two-way process, the teacher not only to teach, but also to mobilize the enthusiasm of students to learn, for different students to develop different learning standards, language level test to be divided into high school low level, teaching and testing combine to stimulate students' learning motivation. Chinese people carry the traditional culture of the 
Chinese nation, so to cultivate students love the enthusiasm of the motherland culture, so that students understand the history of cultural development process understand the crystallization of culture, solid culture foundation. Postmodernist view of knowledge, constructivism and pluralistic intelligence theory are the main theoretical basis of basic education curriculum and teaching reform and to some extent can be said to be classical theory. But a careful analysis of these educational theories produced by the soil is in the modern education system and the system is relatively perfect Western countries. Therefore, we cannot completely apply these theories, provided that they must be effective with our current educational situation to achieve effective docking. Furthermore, the construction of a new educational system and system of a nation and a nation must not rely solely on the theory and thought of transplantation from another country, but must have a foundation on the basis of national and national cultural soils in line with our primary school language education Reality requires the original theory and thought. However, in practice, this docking has not been achieved. Because of this, Chinese primary school language curriculum and teaching reform despite the vigorous development, but had to face an embarrassing reality: foreign advanced education philosophy and Chinese primary school language education theory, thinking and conflict and the emergence of the Chamber of the struggle, their demands Conflict situation. It can be seen that our primary school language curriculum and teaching reform is not the lack of advanced educational philosophy, but it is really a leading, grassroots educational philosophy. Chinese new educational reform calls for world-class educational thought "master", but the current "ideological soil" and "academic soil" are often conducive to "dwarf" survival and not conducive to "giant" development. Primary school language education has a strong social and cultural historical constraints decided to primary school language education reform are bound to social and cultural changes as the basis. Primary school language Traditional education of the old ideas and theories can successfully exit the stage of history, new ideas and theories can successfully enter the main channel, mainly depends on the new educational theory and ideology to adapt to the accumulation of social and cultural psychology. Therefore, the current reform of primary school language education in China only deepen the reform of the political field, abandon all the mechanisms of power ruling, create a relaxed environment conducive to innovation and cultivate talents, and truly realize the free development of individual spirit in order to promote the original generation and master of thought The emergence of the final guarantee of curriculum and teaching reform to achieve the success of the other side.

\section{The Current Problems of Chinese Language Courses in Primary Schools in China}

The primary school language classroom teaching model is too old. Western education and teaching theory has had a profound impact on Chinese education, but our country has accepted its advantages while accepting its shortcomings. Too much procedural, mechanized teaching mode boring teaching classroom has neglected the cultivation of primary school students' personality and personality, and then neglected the ultimate goal of education and teaching. In the traditional teaching classroom, teachers' teaching work mainly lacks the teaching of knowledge, lacks communication with students to deepen the understanding of knowledge, and students become passive recipients of knowledge, and their judgment ability and intelligence are not cultivated. However, the purpose of modern teaching changes with the times, the purpose of learning is not only to learn books, but also part of the overall quality of students to adapt to the social environment. Obviously, the traditional education and teaching mode is backward, cannot keep up with the pace of development of the times, as educators, to the current teaching purpose to explore the pursuit of teaching is not only the form, more is the essence.

There is a conflict between local culture and foreign culture, and language teaching is affected. With the further implementation of the reform and opening up policy, the western theory of education has been further introduced into Chinese education and teaching practice. However, the current educational situation in China has a problem with the combination of foreign advanced teaching theory, because the same teaching theory cannot be there are differences in the mode of thinking of people living in different cultural backgrounds. Moreover, primary school language 
education has its own uniqueness and is constrained by the social history and culture of our country, which makes the primary school the reform of language education must keep up with the background of the times. Therefore, the differences in language teaching caused by foreign cultures have yet to be adjusted.

The new curriculum objectives have not yet fully adapted to the social and cultural environment. The reform of primary school language curriculum is restricted by the current social environment. To a certain extent, primary school language education is not only an educational content, but also an important bridge for the spread of national culture. The importance of reform cannot be ignored. Chinese outstanding talent is selected through the traditional assessment model, talent selection of this content is clearly in the new curriculum to change the target has not been emphasized, and China has a 1300-year history of the unified examination situation has been deeply rooted among the people, a large part of people cannot accept part of the reason for the new curriculum is that the results of the examination are too important. The examiner is not just a student, a parent, and a person who is about to become a parent. Therefore, the current primary school curriculum reform cannot fully adapt to the social environment, it is necessary to face the pressure of the community.

The language teaching faculty is too weak. The cohesion of excellent faculty has undoubtedly created the prerequisite for curriculum reform. Excellent teachers bring not only knowledge but also ideas to students. The focus of the reform of primary school language curriculum is not only the adjustment of curriculum content, but the comprehensive rectification of the curriculum, which requires the teaching of primary school teachers teaching ideas, mainly the adjustment of ideas and changes in the way of thinking. Because the long-standing examination-oriented educational philosophy enjoys popular support, there are too many teaching staff to test the final results as the purpose of teaching, the face of the new curriculum reform, some did not really remove their own burden, did not completely change their teaching concept, which makes teaching cannot be very good, and the new curriculum has lost its meaning.

\section{The Reform Strategy of Primary School Language Curriculum}

Innovative Classroom Teaching Model. To achieve the new curriculum reform is to better train students cultivate all aspects of the development of students, so as to enhance the level of education and national quality. In general, the new classroom model should be students as the main body, the focus is on the use of classroom personality shaping students, teachers should be objective to treat the nature of students, and to strengthen the training of students' good personality. For example, teachers can use the teaching content in the classroom to stimulate student interest and moderate smile with the ridicule can be active classroom atmosphere and help students to stimulate interest, sincere patience to encourage students to ease the pressure of learning. Also, the teacher should treat students with the development of the eyes, the correct treatment of student differences, should not be different with the students to locate. The so-called treatment with the development of the students is the correct treatment of students' differences, accept the error, and help correct. The difference is not only the result of the sustainable development of education, but also the premise of ensuring the good development of students.

Adjust cultural differences. The difference between the reform of language curriculum education and other curriculum education is that the former involves the study of Chinese culture and plays a very important role in the inheritance of Chinese traditional culture. Therefore, the adjustment of cultural differences is urgent. For the foreign classical teaching concept to bring the culture, consistent treatment principle is "whichever is the essence, to its dross", for the new curriculum reform, not only foreign culture "essence" of reference, more of a traditional culture professor Better education of our local culture, at the same time, educators should pay attention to the traditional culture of innovation, you can learn from foreign outstanding cultural services at the present stage of primary school language curriculum reform.

Achieve The Unity of Teaching Reform and Teaching. The new curriculum reform emphasizes the comprehensive development of students' moral, intellectual, physical and aesthetic. The examination emphasizes the cultivation of learning ability. To achieve the unity of teaching and 
teaching and teaching, it is necessary to adjust the examination content, the test content to the new curriculum materials as the basis, not beyond this range, and written examination should not continue to be as a focus, practical assessment should also be concerned about. In the final results of the examination, the written examination results and practical examination scores each accounted for a certain proportion, together constitute the test scores. The realization of the unity of teaching and teaching reform is conducive to alleviating the social contradictions caused by the parents and students due to the examination system. It is also an opportunity to promote the reform of primary school language curriculum.

Strengthen the construction of teachers. The goal of the new curriculum reform requires primary school language teachers not only need to have excellent professional knowledge, but also need to education, psychology and other conditions of knowledge and practical knowledge and other content have a certain understanding. Therefore, to strengthen the construction of teaching staff, the school administrative departments should pay attention to participate in the construction of primary school language curriculum reform teachers, and carry out occasional assessment work to check the teacher's teaching work and check the effect of the new curriculum. At the same time, schools can strengthen the exchange of schools with other primary school language curriculum reform, send a teaching team to conduct field research, conditional, you can choose to send teachers to study in order to facilitate the school to carry out the teaching work. In addition, the school can set the reward system, reward and punishment of the ultimate goal of the system to ask the work of teachers, teachers who are responsible for the work to be rewarded, not serious are to be criticized in order to fully mobilize the enthusiasm of teachers.

\section{Conclusion}

As the forerunner of the current reform of the new curriculum, educators need not only need their own excellent professionalism as the support, but also need to have a development vision to deal with the new curriculum reform. Especially in the curriculum reform of primary school language courses, the education of the early childhood has a very important impact on the future study and life of children. The importance is obvious. Therefore, this reform requires more education workers' efforts, not just in education, but also in the educational philosophy. In general, only the combination of scientific and creative education and creativity can further enhance the level of education in order to cultivate more leaders through education.

\section{References}

[1] Kai Liu: Chinese Campus Education, Vol. 7 (2017) No 53, p.25-26

[2] Yumin Ma: New Campus, Vol. 12 (2015) No 27, p.74-76

[3] Qin Guo: Guangxi Normal University, Vol. 1 (2006) No 33, p.11-14

[4] Jieming Liu: The New Course, Vol. 3 (2007) No33, p.121-124

[5] Xiaohong Yang. Chinese Education, Vol. 6 (2014) No 53, p.25-26 